\title{
Some Ecological and Biological Studies on Typhlodrompis swirskii (Athias-Henriot) (Acari: Phytoseiidae)
}

\author{
M. A. Zaher, Shahira A O. El-Bishlawy and Fatma S. Ali \\ Zoology and Agric. Nematology Dep., Faculty of Agriculture, Cairo University, Egypt
}

\begin{abstract}
Relative humidity of 70 to $85 \%$ proved to be the most suitable for Typhlodrompis swirskii (Athias-Henriot) at $25^{\circ} \mathrm{C}$ as it accelerated development (10.0 \& 10.8 days) and increased female fecundity $(13.0 \& 12.0$ eggs/o/10 days) on Eutetranychus. orientalis immatures. Low temperature $\left(5 \& 9^{\circ} \mathrm{C}\right)$ prolonged egg incubation and decreased hatchability as well as female survival. After one to four weeks, egg hatchability ranged from 90 to $50 \%$ and from 100 to $64 \%$ and female survival from 50 to $0 \%$ and from 80 to $10 \%$ at 5 and $9^{\circ} \mathrm{C}$, respectively. Multiple mating due to male company through the whole female longevity or sporadically for 12 hours every 5 days increased female fecundity and longevity as it averaged $47.0 \& 35.0$ eggs and $37.6 \& 35.0$ days compared with 25.0 eggs and 29.2 days for once mated female. For food attraction and /or kairomone emitted that affects predator, $T$. swirskii females showed greater percentage of attractance in a shorter period to more advanced prey stage and to mites than insects tested. Also fed females showed more attraction than 24 starved females and the latters better than 48 hours starved ones. E. orientalis adults gave the greatest percentage attraction $(60 \%)$ in the shortest time (3.20 minutes) for fed female, while castor been pollens gave the smallest (1\%) and the longest time (121.6 minutes). Host plants of different leaf texture, affected female fecundity, averaging the greatest $(15.8 \mathrm{eggs} / q / 10$ days $)$ on smooth leathery leaf of grape fruit, while coarse reticulated leaf of guava resulted in the least number of deposited eggs (10.8 eggs/ $+/ 10$ days).
\end{abstract}

KEY WORDS: Typhlodrompis swirskii, Phytoseiidae, biology, low temperature, R. H. \%, mating, attraction, host plant.

\section{INTRODUCTION}

Different ecological and biological factors such as relative humidity, low temperature, multiple mating, attraction of predator to its prey and host plant leaf surface have some effects on the bioactivities of plant inhabiting mites including the phytoseiids of which some are considered of great economic importance as biocontrol agents. Of these factors, atmospheric relative humidity and temperature are important that determine the existence of a mite in a certain locality as it affects female mite survival and oviposition (Gillespie and Ramey, 1988, and Takahashi and Chant, 1994).

Observations on mating behavior of the phytoseiids were reported by Shehata, (1967), Amano \& Chant (1978), Overmeer et al. (1982) and several others. Many species oviposit only after insemination of which some females accept only one copulation, while others receive more than one. Kairomones is an interspecific messenger substance that benefits the receiver i.e., the predator but not the releaser i.e., prey. This phenomenon is an important factor in pest biological control. Also leaf surface texture has an obvious influence on the biology of phytoseiids (Rasmy, 1977, and Fouly, 1982). On the other hand, (Walter 1992) found a relationship between both morphology and occurrence of phytoseiid mites and leaf surface texture.

Typhlodrompis swirskii (A. H.) is a worldwide phytoseiid predator and common in Egypt on different fruit trees (Zaher, 1986). Therefore, the objective of this study was to contribute a better understanding on the effect of relative humidity, low temperature, multiple mating, attraction of the predator to different prey and pollen grains and host plant leaf surface on the tested predatory mite T. swirskii.

\section{MATERIALS AND METHODS}

Culture of $T$. swirskii was established in the Acarology laboratory of the Faculty of Agriculture, Cairo University. To investigate the effect of some ecological factors on this predatory mite the following experiments were conducted.

\section{Effect of Relative Humidity:}

Four groups each of 20 newly deposited eggs were confined solitary to upper surface of mango leaf discs kept on wet cotton wool pads in Petri dishes. The hatched larvae were supplied with immatures of the citrus brown mite Eutetranychus orientalis (Klein) till reaching adulthood. Emerging females were mated with fresh males and couples were kept each on a leaf disc to oviposit for 10 days. Experiment was undertaken in dissectors with different solutions of glucose $\mathrm{NaCl}, \mathrm{KCl}$ and $\mathrm{H}_{2} \mathrm{O}$ to maintain four relative humidities 55, 70, 85 and $95 \%$ at $25^{\circ} \mathrm{C}$ for the four groups.

\section{Effect of Low Temperature:}

Eight groups, each of 20 newly deposited eggs of T. swirskii, were placed on mango leaf discs in a covered cylindrical plastic cup $(2.8 \mathrm{~cm}$ diameter and $2 \mathrm{~cm}$ deep) with filter paper on its bottom. Relative 
humidity was maintained by adding few water drops on the filter paper when needed. Four cups were kept at $9^{\circ} \mathrm{C}$ and the other four at $5^{\circ} \mathrm{C}$. One cup with 20 eggs for every temperature was moved to room temperature after one, two, three and four weeks. Egg incubation period and hatchability were recorded. Also, eight groups each with 20 newly emerged and mated females were confined singly to Munger cages (Munger, 1942) at $9^{\circ} \mathrm{C}$ and $5^{\circ} \mathrm{C}$. Cages were supplied with the citrus brown mite E. orientalis (Klein) immatures when needed as prey and kept at the two aforementioned temperature degrees. One group of adult predator females of every temperature degree was moved to room temperature after one, two, three and four weeks of cooling at 9 and $5^{\circ} \mathrm{C}$ to examine female survival, preovipostion and oviposition periods, number of oviposited eggs and hatchability percentage.

\section{Effect of Single and Multiple Mating:}

Three groups, each with $10 \mathrm{~T}$. swirskii newly emerged females, confined singly to mango leaf discs of $4 \mathrm{~cm}^{2}$, were placed on wet cotton wool pads in glass Petri dishes $(9 \mathrm{~cm}$ in diameter). A young male was introduced to every female of the three groups. After first copulation occurred, males were taken away from females of the first and second group, while those of the third group were left with females to live as couples allover females longevity. A newly young male was introduced to every female of the second group for 12 hours sporadically every 5 days for copulation and removed throughout female longevity. Experiment was carried out at $25^{\circ} \mathrm{C}, 70 \pm 5 \%$ R.H. and 12 hours light. E. orientalis immatures were used as prey and female longevity and fecundity were recorded.

\section{Attraction to Different Prey and Pollens:}

T. swirskii females were tested singly to investigate the attraction to different prey species and stages; eggs, immatures and adults of the citrus brown mite E. orientalis and the spider mite Tetranychus urticae Koch; eggs and immatures of the flat mite Cenopalpus pulcher (C.\&F.); eggs and $1^{\text {st }} \& 2^{\text {nd }}$ instars of the whitefly nymph Bemisia tabaci (Gennadius); adults of the aphid Aphis duranta Theo; and the moving stages of the eriophyid mite Cisaberoptus kenyae Keifer; and the pollen grains of the date palm and castor bean at Laboratory temperature $25^{\circ} \mathrm{C} \pm 1{ }^{\circ} \mathrm{C}$. Eight adults, 15 immatures and 20 eggs of each prey and 30 individuals of the eriophyid mite were used in the three experiments. Tested Prey individuals were placed upside down attached to a small piece of both side sticky scotch tape stuck on circumference of a wide mango leaf disc, $4 \mathrm{~cm}$ diameter, at equal distances about $1 \mathrm{~cm}$ from each other. Ten of each fed and $24 \& 48$ hours starved predator females were put singly in a successive order in the center of the leaf disc and kept under observation till reaching its preferable food.

\section{Effect of Host Plant Leaf Surface:}

Leaf discs of different surface texture were used as substratum. Three leaves were of grape fruit (Citrus paradisi (McFad), young mango leaves (Mangifera indica L.) as a thick smooth surface, mulberry (Morus alba L.) and bauhinia (Bauchenia verie-gata) as smooth reticulated surface and guava (Psidium guajava L.) as coarsely reticulated surface. The leaf discs were put on wet cotton wool pads in Petri dishes $(9 \mathrm{~cm}$ in diameter). Twenty newly emerged and mated $T$. swirskii females were confined singly together with surplus E. orientalis immatures as prey on leaf discs of about one square inch of every plant and kept for oviposition. Deposited eggs per female were recorded daily for the first 10 days of the oviposition. Experiment was conducted at $25^{\circ} \mathrm{C}$ and $70 \% \pm 5 \%$ R.H. and observations were undertaken daily.

\section{RESULTS AND DISCUSSION}

Climatic conditions play an important role in determining the occurrence of a mite in certain locality. Of these conditions, relative humidity is an important factor. Present experiment showed that relative humidity of $70 \& 85 \%$ proved to be the most suitable for $T$. swirskii at $25^{\circ} \mathrm{C}$ as it accelerated development (10.0 \& 10.8 days) and increased female fecundity $\left(\begin{array}{lllll}13.0 & \& & 12.0 & \text { eggs/10 days }\end{array}\right.$ respectively. Before and after this limit reverse results occurred Table (1). Rearing Galendromus helveolus (Chant), Caceres (1990) found no significant differences in its developmental time at R.H. from $76 \%$ to $100 \%$ at $25^{\circ} \mathrm{C}$.

During laboratory mass rearing, cold storage can be practiced when prey is scarce or other food deficiency. In addition, temperature usually drops to $10^{\circ} \mathrm{C}$ or less during some winter nights in upper Egypt. Thus, for these two reasons experiment was conducted to investigate the effect of low temperature at 9 and $5^{\circ} \mathrm{C}$ on $T$. swirskii. Table (2) showed the effect of low temperature at the two previously mentioned temperatures on $T$. swirskii egg incubation and hatchability as well as female survival after 1 to 4 weeks. Egg hatchability ranged from $100 \%$ to $64 \%$ and from $90 \%$ to $50 \%$ at 9 and $5^{\circ} \mathrm{C}$ respectively. Also, female survival changed from $80 \%$ to $10 \%$ and from $50 \%$ to $0 \%$ at the two tested temperature degrees and durations respectively. Thus, it is clear that eggs tolerate low temperature than females. Accordingly, when food is scarce, the eggs can be stored for a month at low 
temperature of $9^{\circ} \mathrm{C}$ or less. (Gillespie and Ramy 1988) found that Neoseiulus cucumeris (Oudemans) (=Ambly-seius cucumeris Oudemans) female survival decreased from $86.9 \%$ after 2 weeks to $63 \%$ after 10 weeks at $9^{\circ}$. In the same respect, (Ali et al 1997) reported that hatch-ability of Phytoseiulus macropilis (Banks) eggs changed from 100 to $84 \%$ at $10^{\circ} \mathrm{C}$ and from 100 to $60 \%$ at $5^{\circ} \mathrm{C}$, while female survival ranged from 100 to $10 \%$ and from 90 to $0 \%$ at the two temperature degrees respectively, after 1 to 8 weeks. Similar results were also found by (Abou El ella 1998) on Amblyseius deleoni (Muma and Denmark).

Some females of the family Phytoseiidae accept only one copulation, while others can be copulated more than once. Multiple mating significantly increased $T$. swirskii female fecundity and prolonged its longevity (47.0 eggs \& 37.6 days) for full company with male followed by (35.0 eggs \& 35.0 days) when male was introduced to female for copulation every 5 days. Female copulated once gave the lowest egg production (25.0 eggs) and shortest longevity (29.2 days). Moreover, female percentage was greater in the progeny of multiple mated females $(70.1 \%)$ than in single mated ones (55.0\%) Table (3). Amano and Chant (1979) reported that multiple complete mating resulted in transfer of one or two large spermatophores in every one of the two spermathicae. This usually occurred in females of laboratory colonies. However, the spermatophores, usually disappeared in old females, while in older females some had another spermatophore due to repeated mating (Overmeer et al 1982). Abou El-Ella (1998) found that A. deleoni
(Muma and Denmark) females confined with males as couples during its longevity deposited greater number of eggs in a shorter period than those coupled with male for 24 hours every 10 days or females copulated once.

Response of the predator to its prey due to kairomones emitted by the prey play an important role in biological control. Kairomones are specific as that attract one predator does not attract others. Also infested leaves are kept attractant to the predator for sometime after removing the pest (Sabilis \& van de Baan, 1983). Table (4) indicated that T. swirskii females showed hierarchy of preference for Kairomones released from different prey or pollens. T. swirskii females showed greater percentage of attractance in a shorter period to more advanced prey stage and to mites than insects tested. E. orientalis adults gave the highest attraction $60 \%$ in the shortest time 3.2 minutes for fed females. This is followed in a descending order by E. orientalis immatures $8 \%$ \& eggs $5 \%$; date palm pollen $10 \%$; C. pulcher (C. \& F.) immatures $4 \%$ \& eggs $2 \%$; T. urticae Koch adults $2 \%$, immatures $1 \%$ \& eggs B. tabaci $2^{\text {nd }} \& 1^{\text {st }}$ instar nymph $2 \& 1 \% ;$ A. duranta adults $1 \%$; the eriophyid $C$. kenyae moving stages $1 \%$ and castor bean pollens $1 \%$. The time required for fed $T$. swirskii female to reach its food ranged from 3 minutes for $E$. orientalis adults to 121.6 minutes for castor bean pollens. The fed predator females generally showed more attraction percentage and in shorter time than those starved for 24 hours and the latters less than females starved for 48 hours Table (4). This may be due to the weakness of the starved females.

Table (1): Effect of relative humidity on egg hatchability, life cycle and female fecundity of Typhlodrompis swirskii fed on Eutetranychus orientalis at $25^{\circ} \mathrm{C}$

\begin{tabular}{lcccc}
\hline \multicolumn{1}{c}{ R.H. } & $55 \%$ (glucose) & $70 \%(\mathrm{NaCl})$ & $85 \%(\mathrm{KCl})$ & $95 \%\left(\mathrm{H}_{2} \mathrm{O}\right)$ \\
\hline Hatching $\%$ & $100 \%$ & $100 \%$ & $100 \%$ & $100 \%$ \\
\hline Incubation period (days) & $4.0 \pm 0.70$ & $3.0 \pm 0.70$ & $3.0 \pm 0.71$ & $4.0 \pm 0.70$ \\
\hline Life cycle (days) & $11.2 \pm 0.44$ & $10.0 \pm 0.70$ & $10.8 \pm 0.44$ & $11.0 \pm 0.70$ \\
\hline No. of eggs/ \% for 10 days & $10.0 \pm 0.74$ & $13.0 \pm 0.71$ & $12.0 \pm 0.70$ & $9.0 \pm 0.71$ \\
\hline
\end{tabular}

Table (2): Effect of low temperature on Typhlodrompis swirskii egg incubation period, hatchability, female survival and pre-oviposition period when fed on Eutetranychus orientalis

\begin{tabular}{|c|c|c|c|c|c|c|c|c|}
\hline & \multicolumn{8}{|c|}{ Cold storage time } \\
\hline & \multicolumn{2}{|c|}{1 week } & \multicolumn{2}{|c|}{2 weeks } & \multicolumn{2}{|c|}{3 weeks } & \multicolumn{2}{|c|}{4 weeks } \\
\hline & $9^{\circ} \mathrm{C}$ & $5^{\circ} \mathrm{C}$ & $9^{\circ} \mathrm{C}$ & $5^{\circ} \mathrm{C}$ & $9^{\circ} \mathrm{C}$ & $5^{\circ} \mathrm{C}$ & $9^{\circ} \mathrm{C}$ & $5^{\circ} \mathrm{C}$ \\
\hline $\begin{array}{l}\text { Incubation period (days) } \\
\text { A.C.S. }\end{array}$ & $4.0 \pm 0.70$ & $5.0 \pm 0.70$ & $5.0 \pm 0.40$ & $7.0 \pm 0.00$ & $7.0 \pm 0.54$ & $\begin{array}{l}11.0 \pm \\
0.01\end{array}$ & $9.0 \pm 0.44$ & $15.0 \pm 0.45$ \\
\hline Hatchability \% & 100 & 90 & 88 & 85 & 79 & 75 & 64 & 50 \\
\hline Female survival \% & 80 & 50 & 70 & 20 & 50 & 5 & 10 & 0 \\
\hline Pre-oviposition period (days) & $10 \pm 0.45$ & $14 \pm 0.71$ & $13 \pm 0.63$ & $20 \pm 0.43$ & - & - & - & - \\
\hline Hatchability of eggs \% & 70 & 60 & 40 & 10 & 12 & - & 4 & - \\
\hline
\end{tabular}

A.C.S. $=$ After cold storage 
Table (3): Effect of single and multiple mating on Typhlodrompis swirskii female longevity and fecundity and sex ratio when fed on Eutetranychus oreintalis at $25^{\circ} \mathrm{C}$

\begin{tabular}{lccc}
\hline Matings & No. of eggs/female & Female longevity (Days) & Female \% \\
\hline Female + male allover longevity & $47.0 \pm 0.73$ & $37.6 \pm 0.54$ & 70.1 \\
\hline Female + male 12 hours every 5 days & $35.0 \pm 0.71$ & $35.0 \pm 0.70$ & 70.1 \\
\hline Single mating & $25.0 \pm 0.70$ & $29.2 \pm 0.44$ & 55.0 \\
\hline
\end{tabular}

Table (4): Attraction of Typhlodrompis swirskii female to different prey and pollens at $25^{\circ} \mathrm{C}$

\begin{tabular}{|c|c|c|c|c|}
\hline \multirow{2}{*}{ Food } & \multicolumn{4}{|c|}{ Time in minutes for predator $q$ to reach prey and pollens } \\
\hline & Fed & Starved $(24 \mathrm{~h})$ & Starved $(48 \mathrm{~h})$ & Attraction \% \\
\hline \multicolumn{5}{|l|}{ E. orientalis } \\
\hline Adults & $3.20 \pm 1.03$ & $8.20 \pm 0.78$ & $10.70 \pm 0.82$ & 60 \\
\hline Immatures & $6.10 \pm 0.87$ & $9.30 \pm 1.05$ & $12.90 \pm 0.73$ & 8 \\
\hline Eggs & $10.70 \pm 0.82$ & $13.00 \pm 0.81$ & $70.00 \pm 0.81$ & 5 \\
\hline Date palm pollen & $7.20 \pm 0.78$ & $10.80 \pm 0.78$ & $14.40 \pm 0.96$ & 10 \\
\hline \multicolumn{5}{|l|}{ C. pulcher } \\
\hline Immatures & $13.80 \pm 0.91$ & $17.80 \pm 0.78$ & $23.90 \pm 0.73$ & 4 \\
\hline eggs & $16.30 \pm 0.67$ & $20.90 \pm 0.87$ & $28.20 \pm 0.78$ & 2 \\
\hline \multicolumn{5}{|l|}{ T. urticae } \\
\hline Adults & $19.40 \pm 0.96$ & $24.10 \pm 0.73$ & $31.40 \pm 0.78$ & 2 \\
\hline immatures & $34.20 \pm 0.78$ & $39.40 \pm 0.96$ & $45.10 \pm 0.73$ & 1 \\
\hline eggs & $43.30 \pm 0.94$ & $50.20 \pm 1.03$ & $53.70 \pm 0.82$ & 1 \\
\hline \multicolumn{5}{|l|}{ B. tabaci } \\
\hline $2^{\text {nd }}$ instar nymph & $47.60 \pm 0.96$ & $53.70 \pm 0.67$ & $59.30 \pm 0.94$ & 2 \\
\hline $1^{\text {st }}$ instar nymph & $51.10 \pm 0.73$ & $57.20 \pm 0.78$ & $64.10 \pm 0.87$ & 1 \\
\hline Eggs & $56.90 \pm 0.87$ & $62.70 \pm 1.15$ & $67.90 \pm 0.73$ & 1 \\
\hline \multicolumn{5}{|l|}{ A. duranta } \\
\hline Adults & $67.60 \pm 0.96$ & $73.90 \pm 0.99$ & $81.30 \pm 0.94$ & 1 \\
\hline \multicolumn{5}{|l|}{ C. kenyae } \\
\hline moving stages & $81.20 \pm 1.03$ & $91.30 \pm 0.94$ & $97.50 \pm 1.26$ & 1 \\
\hline Castor bean pollens & $121.60 \pm 1.50$ & $141.60 \pm 1.07$ & $162.0 \pm 1.33$ & 1 \\
\hline
\end{tabular}

Table (5): Effect of host plant leaf surface on female Typhlodrompis swirskii, development and oviposition, when fed on Eutetranychus orientalis

\begin{tabular}{lcc}
\hline \multicolumn{1}{c}{ Plant } & Life cycle (days) & No. of eggs/\&/10 days \\
\hline Citrus paradisi (Grape fruit) & $8.85 \pm 1.21$ & $15.80 \pm 1.09$ \\
\hline Mangifera indica (Mango) & $10.80 \pm 1.09$ & $13.20 \pm 0.83$ \\
\hline Malus sylvestris (Apple) & $11.60 \pm 0.54$ & $12.60 \pm 0.54$ \\
\hline Morus alba (Mulberry) & $11.83 \pm 0.75$ & $11.50 \pm 0.54$ \\
\hline Bauchenia veriegata (Bauhinia) & $12.16 \pm 0.40$ & $11.20 \pm 0.44$ \\
\hline Psidium guajava (Guava) & $12.60 \pm 0.54$ & $10.80 \pm 0.44$ \\
\hline
\end{tabular}

Other ecological factor is plant leaf surface texture. It showed obvious influence on $T$. swirskii biology. Smooth leathery leaf of grape fruit accelerated development and increased female fecundity (8.85 days and 15.8 eggs/10 days), while coarse reticulated leaf of guava gave opposite results (12.6 days and 10.8 eggs/10 days) (Table 5). Moderate results occurred on leaves with textures ranged between the two above mentioned host plants. Accordingly, coarse texture of the leaf may hinder the searching capacity of the predator. However, other factors such as leaf glands, chemical and water contents may have effects on the acarine prey and predator biology and occurrence. Finally, it can be concluded that the aforementioned ecological factors showed obvious effects on the different activities of the phyoseiid predator T. swirskii. These factors may be put in consideration with regard to the predatory mite mass rearing cultures and to its occurrence in the field. 


\section{REFERENCES}

Ali, Fatma S; Mowafi, M. M. and El-Sherif, A. A., 1997. Some factors affecting the biology of the predatory mite, Phytoseiulus macropilis (Banks) (Acari: Phytoseiidae). Bull. Ent. Soc. Egypt., 75 (19): 19-26.

Abou-Elella, G. M. A., 1998. Studies on certain aspects of some predaceous phytoseiid mites. $\mathrm{Ph}$. D. Thesis, Fac. of Agric., Cairo University, 183 PP.

Amano, H. and Chant, D. A., 1979. Mating behaviour and reproductive mech-anisms of two species of predaceous mites, Phytoseiulus persimilis Athias- Henriot and Amblyseius andersoni (Chant) (Acarina: Phytoseiidae). Acarologia, (20): 196-213.

Blommers, L., 1976. Some Phytoseiidae (Acarina: Mesostigmata) from Mada-gascar, with description of eight new species and notes on their biology. Bijdrangen Tot de Dierkunde. (46): 81-105.

Caceres, S., 1990. Biology and life tables of Galendromus helveolus (Chant) (Acari: Phytoseiidae), a spider mite predator, on Florida citrus. M. Sc. Thesis, Graduate School, Florida Univ., 62 PP.

Fouly, A. H., 1982. Studies on Phytoseiid mites. M. Sc. Thesis, Fac. Agric., Mansoura Univ., 93 PP.

Gillespie, D. R. and Ramey, C. A., 1988. Life history and cold storage of Amblyseius cucumeris (Acarina: Phytoseiidae). J. Ent. Soc. Br. Columbia, 85 (31): 71-76.

Kennet, C. E., 1958. Some predaceous mites of the subfamilies Phytoseiinae and Aceosejinae (Acarina: Phytoseii-dae, Aceosejidae) from central California with description of new species. Ann. Ent. Soc. Am., (51): 471-479.

Overmeer, W. P. J.; Doodeman, M. and van Zon, A. Q., 1982. Copulation and egg production in Amblysius potentillae and Typhlodromus pyri (Acari: Phytoseiidae). Z. ang. Ent.,(93): 1-11.

Rasmy, A. H., 1977. Predatory efficiency and biology of the predatory mite Amblyseius gossipi (Acarina: Phytoseiidae) as affected by plant surfaces. Entomophaga, (22): 421-423.

Sabelis, M. W. and van de Baan, H. E., 1983. Location of distant spider mite colonies by phytoseiid predators: demonstration of specific kairomones emitted by Tetranychus urticae and Panonychus ulmi. Entomol. Exp. Appl., (33): 303-314.

Shehata, K. K., 1976. Survey and biological studies on mites of family Phytoseiidae and its economic importance Ph.D. Thesis, Fac. Agric., Cairo Univ., 371 PP.

Takahashi, Fumio and Chant, D. A., 1994. Adaptive strategies in the genus Phytoseiulus Evans (Acari: Phytoseiidae) survivorship and reproduction. Internat. J. Acarol., 20 (2): 87-97.

van der Merwe, G. G., 1968. A taxonomic study of the family Phytoseiidae (Acari) in south Africa with contributions to the biology of two species. Ent. Mem. Dep. Agric. Tech. Serv. Repub. S. Afr., (18): 1-198.

Walter, D. E., 1992. Leaf surface structure and the distribution of Phytoseiulus mites (Acarina: Phytoseiidae) in south Australian forests. Aust. J. Zool., 40: 593-603.

Zaher, M. A., 1986. Survey and Ecological studies on Phytophagous, Predaceous and soil mites in Egypt. II- Predaceous and Non-Phytophagous Mites. PL 480 Program, U.S.A., Fac. Agric., Cairo Univ. Egypt., 567 PP. 